http://dx.doi.org/10.12795/PH.1992.v07.i01.07

\title{
ELEMENTOS RITUALES Y FORMALES EN LA TRILOGIA INACABADA DE FEDERICO GARCIA LORCA
}

Mercedes Vílchez Díaz

In the following paper the authoress reviews some features of Lorca's works which appear to be parallel to basic features of Ancient Greek Lyrics. She also notes the great influence which Aeschylus's plays caused on Lorca's unfinished trilogy.

\section{INTRODUCCIÓN}

El presente artículo es producto de la reelaboración de una Conferencia dictada en la Universidad de Sevilla, el curso 1990-91, con motivo de un Ciclo interdisciplinar de Hispánicas y Clásicas.

Yo, como todo el mundo, había leído reiteradamente el teatro y la poesía de Lorca. Pero nunca hasta ahora había estudiado las Conferencias, las cartas, las entrevistas' ${ }^{\prime}$. Nunca hasta ahora me había puesto en contacto con especialistas en el tema y con su familia².

De todo ello he sacado algunas conclusiones que pueden ser de utilidad.

1 He utilizado los siguientes textos: Obras completas con Prólogo de Jorge Guillén y Epílogo de Vicente Aleixandre. Madrid, 1967; y los tres volúmenes editados por M. García - PusAi)A, Akal, Madrid, 1980. 1982.

2 Debo mi agradecimiento al magnífico especialista en Lorca, mi compañero y amigo Miguel García Posada, que también me indicó el camino para ponerme en relación con su familia. 


\section{IDEAS PARA UNA TRILOGÍA Y SUS FUENTES}

La idea que tuvo Lorca de construir una trilogía y también su concepción del «teatro total», lleva, inevitablemente, a plantearse un primer problema; es éste: sus fuentes de conocimiento de la literatura clásica.

Esto me ha llevado a analizar su obra como creación inmersa en unas vivencias que, desde su casa natal de Granada, en la que está su biblioteca personal ${ }^{3}$, pasan por la Residencia de Estudiantes de la calle Pinar 21 y Fortuny 30 de Madrid, luego por su breve estancia en Estados Unidos, volviendo a Madrid, a la Residencia en los «momentos de compromiso» en que se creó el grupo teatral «La Barraca» a una, tal vez añorante, vuelta a Granada, que le costó la vida absurdamente ${ }^{4}$.

Hay que reconstruir, pues, una cronología.

- En la biblioteca particular del pocta hay un ejemplar en español de la Teogonía de Hesiodo, lleno de anotaciones en los márgenes. Hay un texto de Shakespeare en inglés que, sin duda, no leyó nunca. El inglés de Lorca era muy rudimentario. Incluso el tiempo que pasó en Nueva York, ante el asombro que le causaba que un camarero pudiera hablar inglés y él no, se matriculó en Cursos para Extranjeros y, se nos dice que, sin hacer grandes progresos.

- El paso siguiente para reconstruir sus lecturas hay que buscarlo en la Residencia de Estudiantes, donde estuvo desde el año 1918 hasta el 1928.

De ese lugar hay una descripción deliciosa. Procede de su famosa Conferencia «Teoría y juego del duende», pronunciada en Buenos Aires a comienzos de 1934, ya con cierta lejana perspectiva.

«Desde el año 1918, que ingresé en la Residencia de Estudiantes de Madrid hasta 1928, en que la abandoné, terminados mis estudios de Filosofía y Letras, he oído en aquél refinado salón donde acudía para corregir su frivolidad de playa francesa la vicja aristocracia española, cerca de mil conferencias.

Con ganas de aire y sol, me he aburrido tanto, que al salir me he sentido cubierto por una leve ceniza casi a punto de convertirse en pimienta de irritación.

No. Yo no quisiera que entrase en la sala ese terrible moscardón del aburrimiento, que ensarta todas las cabezas por un hilo tenue de sueño y pone en los ojos de los oyentes unos grupos diminutos de puntas de alfiler».

Quizá en ninguna parte como en este fragmento de Lorca se encuentra una descripción más certera de aquellos cenáculos de la cultura, no exentos de dogmatismo y, por lo tanto, de ridiculez.

Pero hay un dato muy importante «para curar su frivolidad de playa francesa». 
Ciertamente la única cultura era la francesa. El ambiente: muy alto en las personas a las que la «naturaleza» les concedió el don del señorio de alma: allí se juntaron Aleixandre, Marquina, Buñuel, Juan Ramón Jiménez, Gregorio Martínez Sierra, el director de la Residencia era Alberto Jiménez Fraud. Eran gentes muy escogidas, pero pocas en número. No se puede pensar que sus ideas se hicieran extensivas a las masas vinculadas con esos círculos. Igual sucedió con las doctrinas laicas de la democracia ateniense.

De modo que «La cultura francesa» a la que alude Lorca es perfectamente compatible «con el moscardón del aburrimiento».

Ahora lo que interesa es la cultura francesa real: Cernuda nos dice que él leyó la Antología Palatina en la edición francesa de la colección Budé.

En la casa próxima de la calle Fortuny, Colegio Mayor en el que yo estuve muchos años después, había libros de la Budé con el sello de la Residencia de Estudiantes..

El resto de los textos de los autores griegos en francés: o se perdieron, tal vez fueran a parar a colecciones particulares; o se salvaron llevándolos a la Biblioteca general del Consejo, en la cercana calle Serrano.

Lo cierto es que después de la guerra en la calle Pinar no había libros. Es posible que durante la guerra, en que esa casa fue Hospital; se perdieran muchos libros y otros se salvaran llevándolos a edificios cercanos más seguros.

No es posible saber con certeza si Lorca leyó la literatura griega tan sólo en las malas traducciones existentes. Un buen estudioso del poeta piensa que su francés no era tan bueno como para enteder a Esquilo. Los datos fidedignos conducen a postular que de las personas allí reunidas era Dámaso el único que leía con soltura diversas lenguas.

Yo tengo mis dudas: creo que es posible y se puede postular que un hombre inteligente y culto captara perfectamente la obra de Esquilo en su traducción francesa en una época en que la única cultura era la francesa.

También se sabe que en la Residencia eran frecuentes las reuniones en las que se hacían lecturas públicas tomando el té. Ese hecho lleva a postular que Lorca fue un buen oyente y un oyente muy selectivo.

Por la evolución de su obra se puede postular que su contacto con los clásicos no fue temprano. Los datos más antiguos me llevan a los 25-26, no antes.

Hay varios hitos que pueden corroborarlo: El primero data del 13 de febrero de 1926. El segundo de mayo de 1927.

A ellos voy a hacer alusión brevemente:

1. La lectura de Góngora fue una fuente de aproximación de Lorca a la cultura clásica en profundidad, a muchas temáticas míticas. De Góngora aprendió «que es su obra un problema de comprensión. A Góngora no hay que leerlo, sino estudiarlo, no viene a buscarnos, sino que hay que perseguirlo razonablemente». Igual sucede con Esquilo, que le debió causar una impresión muy profunda. 
Lorca encuentra una explicación a ese hecho, dice: Era de Córdoba y sabía latín como pocos. No hay que buscarlo en la historia, sino en su alma»s.

De la lectura de Góngora nace su descripción de la metáfora, frente al resto de las imágenes: «La metáfora une dos mundos antagónicos por medio de un salto equestre de la imaginación». Sin saberlo, está cerca de la definición de Aristóteles

2. En mayo del año 1927, en Cadaqués, en la casa de Dalí, trabajaba en una obra titulada nada menos que El sacrificio de Ifigenia.

Es evidente que, aunque fuera en unas primeras lecturas, conocía la tragedia griega $y$, sin duda, la de Esquilo.

Durante los años entre el 27 y el 30 debió releer una y otra vez a los trágicos griegos. Esta parece ser la situación cuando el día 25 de julio del año 1928, mirando el $A B C$ en la Residencia encontró una noticia: era la crónica del trágico desenlace de unas bodas campesinas en un cortijo de Níjar, en Almería.

Ese hecho real dio lugar a diversos romances populares que en el año 1977 se conocían todavía.

Es curioso que Lorca tomara su tema de Bodas de una historia real. Es muy curioso porque ese simple hecho hay que situarlo dentro y junto al teatro de su época. El haber tomado un hecho real, escrito en la prensa, del que corrieron luego leyendas, no es otra cosa que remitirse a una saga. Por Saga entiende un griego de época arcaica y clásica «la narración de acontecimientos que sucedieron en verdad, aunque el poeta no fue testigo presencial de ellos». Es saga lo que utilizaban los trágicos como material básico; y sólo en algunos casos se convierte en mito. Esto sucede únicamente cuando la saga se utiliza como un paradigma atemporal, universal, una alegoría y, como cualquier símil o metáfora, es utilizable para historiar otra realidad ${ }^{6}$.

Así que, con tranquilidad, se puede sostener que en Bodas y Yerma hay saga convertida en mito..

Porque la saga de lo ocurrido en un cortijo de Níjar le sirve al poeta para historiar la sociedad de su tiempo.

Se suele decir que lo que refleja Lorca es la oposición entre libertad y autoridad. Yo creo que eso no es falso; tan sólo pienso que requiere alguna matización que va más lejos, ésta: yo diría que lo que presenta Lorca es la oposición entre naturaleza y convención.

De esta fecha data la idea inicial de escribir Bodas. Por ello Lorca considera que tardó cinco años en elaborar la obra.

El 14 de septiembre de 1932 leyó Bodas de sangre en la casá del diplomático chileno Carlos Morla.

- Cf.: La imagen poética de Don Lais de Góngoray Imaginación, inspiración. evasioin, recogidas en la edición

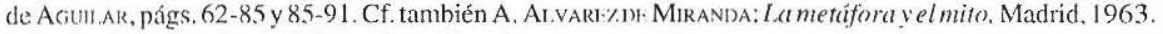

6 Cf. mi trabajo Mitologia, Mito y Tragedia griega (en prensa). 
El 8 de marzo de 1933 fue su estreno. Con esa ocasión, dijo Lorca en una entrevista publicada por José Sánchez Serna: Bodas de sangre es la parte primera de una trilogía dramática de la tierra española. Estoy, precisamente estos días, trabajando en la segunda, sin título aún, que he de entregar a la Xirgu. ¿Tema? La mujer estéril. La tercera está madurando ahora dentro de mi corazón. Se titulará La destrucción de Sodoma ${ }^{7}$.

Ni Bodas niYerma se entienden sin el teatro de Esquilo y, tampoco la idea de construir una trilogía.

Yerma la escribió entre 1933-34. Lola Membrives lo presionó, en América, para que se diera prisa en su redacción. La leyó el 3 de diciembre del 34 en casa de Morla. Se estrenó el 29 en Madrid. La representó Margarita Xirgu, en medio de un «intento de reventamiento» por parte de jóvenes derechistas, que iba dirigiendo contra la Xirgu, amiga de Azaña.

Algunos sectores de la prensa conservadora reprocharon la obra por su crudeza de lenguaje y su paganismo.

Se lee en los hispanistas el término fatum aplicado a la trilogía inacabada. No es correcto ni ese término, ni ese concepto.

Toda la vida nos hemos dedicado los estudiosos de clásicas a explicar a nuestros alumnos que, en el pensamiento griego siempre hay libre elección por parte del hombre; aún en los casos de poctas teocéntricos que, reconocen la existencia de otra esfera, bastante perturbadora por cierto, que es la divina. Son dos contrarios afirmados con fuerza: no existe el fatum, un destino implacable.

Tanto los protagonistas de Bodas como la heroina de Yerma eligen su acción, su drân y su elección es trágica que no significa otra cosa que una recurrencia de dilemas: Ante una circunstancia dada el hombre ha de elegir en solitario y, por supuesto cargar con las consecuencias de su elección, o sea, con su responsabilidad.

Eso es tragedia, no fatum y, es tragedia griega, que nunca cristiana, por la simple razón de que en el Cristianismo no puede existir el concepto de lo trágico.

\section{IDEAS PARA CREAR UN TEATRO POÉTICO Y SUS FUENTES}

\section{III.1. Del teatro de guiñol al «teatro total»}

Es muy sorprendente el paso del teatro de guiñol a esas dos grandes obras que son Iragedias: Bodas y Yerma, llenas de corales; con estructuras complejas a base de solista/ coro. Con estructuras líricas que alternan con las dialógicas.

No deja de ser sorprendente que Lorca pusiera en escena fragmentos de las Euménides de Esquilo en Buenos Aires, hecho citato por todos los hispanistas, pero nunca analizado. 
Sólo hay que dejar hablar al propio Lorca. Sus ideas sobre «el teatro total» con música, danza, teatro ritual, con coros. Y hay que tener en cuenta que solamente de la última versión de Mariana de Pineda, que tuvo varias, se conserva la música, como la de Bodas. Todo ello supone una evolución.

Ante esa evolución cabe hacerse algunas preguntas: Cómo y Qué sucedió.

$\mathrm{Y}$ el propio Lorca responde a esas preguntas, si se leen con mente y cultura milenaria sus últimas Conferencias y declaraciones en Entrevistas. De ellas se extrae que entran en juego tres factores aliados. A ellos me refiero ahora:

\section{III.2. Hay que adquirir una cultura clásica habiendo nacido en el Mar Nuestro, en la cuenca del Mediterráneo}

En sus Conferencias de los últimos años cita a Sócrates, en un tex to que parece sacado del Banquete de Platón; del Dionisismo. Se establece una diferencia bien conocida entre angel y musa y duende. En ese texto duende no es otra cosa que el término que hace referencia al daimón socrático. Dice así Lorca:

«El duende está en las raíces de la cultura mediterránea que son griegas. Duende es lo que perseguía Nietzsche, sin encontrarlo y sin saber que el duende que él perseguía había saltado de los misteriosos griegos a las bailarinas de Cádiz.

Así, pues, no quiero que nadie confunda al duende con el demonio teológico de la duda, al que Lutero, con un sentimiento báquico, le arrojó un frasco de tinta en Nuremberg, ni con el diablo católico, destructor y poco inteligente, que se disfraza de perra para entrar en los conventos.

No. El duende de que hablo, oscuro y estremecido, es descendiente de aquel alegrísimo demonio de Sócrates, mármol y sal que lo arañó indignado el día en que tomó la cicuta...».

«Es diferente el angel y la musa; de ellos aprendió Hesiodo. Angel y musa vienen de fuera: el angel da luces y la musa da formas, -Hesiodo aprendió de ellas, el poeta recibe normas en su bosquecillo de laureles. En cambio, al duende hay que despertarlo en las últimas habitaciones de la sangre...».

«La virtud mágica del poema consiste en estar siempre enduendado para bautizar con agua oscura a todos los que lo miran, porque con duende es más fácil amar, comprender, y es seguro ser amado, ser comprendido»".

En suma, creo que en toda la cuenca del Mediterráneo, y sobre todo en algunos lugares muy cercanos al mar existe una visualización de los colores, un olfato de los olores, una visualización de las formas, del barroco más cargado, convertido en mesura, por el ritmo 
de los hombres. Mucho oro hay, pero no ofende; a eso un buen día se le llamó clásico. No se equivocaba Lorca, porque clásico es sólo algo que dice siempre. Y ese «algo que dice siempre» no es otra cosa que una enorme desarmonía de colores, olores y sonidos que, por obra de la forma, sea ella escultura, ritmo, danza, se convierten en equilibrio.

Lorca no empezó sabiendo, empezó conociendo. Ningún trabajo le debió costar entender la literatura griega, debió ser para él una fiesta íntima solamente, como fue para otros.

\section{III.3. Un teatro vinculado a un «compromiso histórico»}

En el Discurso de despedida de Buenos Aires, el 10 de marzo de 1934 dijo Lorca:

«Voy a leer el primer cuadro de la tragedia Yerma,donde se planta de lleno el asunto, y después el primer cuadro del segundo acto, donde yo desarrollo un coro, recibiendo la luz de normas antiguas pero eternas en el teatro trágico»?.

En una Entrevista que le hizo Juan Chabás en 1934 sobre su teoría de la tragedia, opina así: «Ahora voy a terminar Yerma, una segunda tragedia mía. La primera fue Bodas de sangre. Yerma será la tragedia de la mujer estéril. El tema, como usted sabe es clásico, pero yo quiero que tenga un desarrollo y una intención nuevos. Una tragedia con cuatro personajes principales y coros, como han de ser las tragedias. Hay que volver a la tragedia. Nos obliga a ello la tradición de nuestro teatro dramático. Tiempo habrá de hacer comedias y farsas. Mientras tanto yo quiero dar al teatro tragedias» ${ }^{10}$.

Estas declaraciones están en relación con «su compromiso histórico», al aceptar la dirección de La Barraca, aprobada en marzo de 1932 por el Ministerio de Instrucción Pública de la segunda República. Se trata de entender la tragedia como enseñanza abierta.

Se habla de las deudas de Lorca a Marquina, deudas sólo temáticas. Se habla de que, formalmente, no se explica sin los precedentes del teatro del Siglo de Oro: Lope y Calderón.

Pues bien, no digo que no sea cierto; pero lo que sostengo es que ese fenómeno no se explica sin las fuentes del primer y verdadero teatro de Occidente, que es el griego ${ }^{11}$.

Que en aquellos años que precedieron al 1934 se hablara de la democracia ateniense, es lo lógico. Que se hablara de los cultos y rituales de toda la cuenca del Mediterráneo era nada más que lo esperable. Del teatro griego, como enseñanza abierta a todos, de sus raíces religiosas. Todo ello era lo lógico.

Lorca fue un gran lector, un buen oyente y, muy selectivo por cierto. Quien lo fascinó fue Esquilo: su obra metafórica, sus grandes coros de acción, la herencia de un crimen de sangre

9 Publicado con el título «Una extraordinaria creación» en Crítica, Buenos Aires 12 de marzo de 1934.

10 «Vacaciones de la Barraca» publicada en Luz, Madrid, el 3 de septiembre de 1934 y «Federico García Lorca y la tragedia» publicada en $\mathrm{Luz}$, Madrid, el 3 de julio de 1934.

"AITRADOS, F. 
en la trilogía La Orestiada; no otra cosa es Bodas. La cerrada recurrencia de temas. Y debió impresionarle mucho los corales de persecución de «Las Euménides, que refleja en Bodas.

De ahí salió luego la idea de una trilogía, al modelo de la única conservada en toda la tragedia griega.

Mi conclusión es que Esquilo desbordó a Lorca y hubiera desbordado a cualquier otro poeta. Me explico a continuación:

1. De la tragedia griega en general nació su idea «de un teatro poético y total».

2. De la lectura de la literatura griega de época arcaica y clásica. Y también de la lectura de la literatura latina -heredera de la griega de época helenística-, nació en él una capacidad para relacionar ritos y cultos: los que existían en su Andalucía natal y los que reflejaban los textos literarios clásicos.

3. De La Orestiada partió su idea de la trilogía inacabada. Es extraño que esa trilogía no se acabara. Es extraño el cambio de nombre para la última de las tragedias en proyecto. Sólo tenía Lorca claro el tema: el incesto.

4. Me creo que fue muy difícil para él aunar forma y tema a lo largo de una trilogía.

La temática de la Orestiada entera la concentró, y sin querer, en Bodas.

Las grandes estructuras formales de Esquilo las explotó mejor en Yerma. En esa obra hay, por otra parte, reminiscencias temáticas de Eurípides.

Utilizar para la tercera obra un título bíblico era imposible. De ahí vino el cambio de título para la tercera obra, que nunca se escribió.

IV. EI.EMENTOS RITUALES Y FORMALES DE L.A LITERATURA GRIEGA EN «BODAS» Y «YERMA»

No se puede establecer una división entre elementos rituales y estructuras formales. Ese es precisamente el dato más relevante de estas obras para poder afirmar sus fuentes en el teatro griego.

No puedo hacer, en tan poco tiempo, un análisis minucioso porque los datos son muchos y muy ricos. Así que sólo voy a centrarme en los rituales y las estructuras formales más importantes de las dos obras.

$\mathrm{Y}$ voy a seguir, como andaluza que soy, intentando reconstruir el camino que pudo recorrer Lorca antes de presentar los datos concretos.

1. En Fuente Vaqueros y, luego en Granada, pudo percibir la dicotomía vida/muerte desde niño. Allí conoció canciones de trabajo, canciones de juegos, refranes de boda, a los que precedían comportamientos por ejemplo: el novio celebraba con hombres la despedida de soltero; la novia no se sabe bien lo que hacía.

En la llegada de la Primavera Lorca conoció los Mayos, acompañados de cuestaciones. Por esa época en Antequera un como de muchachas iba al campo a recoger amapolas entre los trigales. Se inmolaba un cordero en las casas ricas, bien 
alimentado en los campos durante la primavera temprana con alcacé y sacrificado luego, como un fármaco.

Conoció los duelos, ropas negras, se levantaban los rodapies, se cerraba media puerta, los hábitos se mutaban; era un treno.

2. En Madrid convirtió en cultura basada en conocimientos del pasado lo que era su conocimiento «de la cultura de la tierra y la herencia milenaria».

3. Y sólo muy tarde se atrevió a exponer todo aquello en una descripción, en el año 1934 que dice así:

«Parece como si todo el duende del mundo clásico se agolpara en esta fiesta perfecta, exponente de la cultura y de la gran sensibilidad de un pueblo que descubre en el hombre sus mejores iras, sus mejores bilis y su mejor llanto. Ni en el baile español, ni en los toros se divierte nadie; el duende se encarga de hacer sufrir por medio del drama, sobre formas vivas, y prepara las escaleras para una evasión de la realidad que circunda... El duende no se repite, como no se repiten las formas del mar en la borrasca.

En los toros adquiere sus acentos más impresionantes, porque tiene que luchar, por un lado, con la muerte, que puede destruirlo, y por otro lado, con la geometría, con la medida, base fundamental de la fiesta» ${ }^{12}$.

Existió desde época griega, y mucho antes, desde el Neolítico, un juego de culturas que, los pueblos indoeuropeos convirtieron en nuestra cultura. Fue una amalgama: El caballo tema recurrente en Lorca es «el principio masculino, fecundante. La mujer, tema recurrente es el principio femenino, fecundado, pero creador único de vida, de historia», procede de las culturas matriarcales, más antiguas en toda la cuenca del Mediterráneo.

Fue la conjunción la que dio lugar a lo que son culturas y ritos agrarios, donde juega vida/muerte; hombre/mujer; viejo/joven y, en último término naturaleza/convención, que lo engloba todo.

Dentro de ese marco hay que entender la tragedia de Lorca. Verdaderamente, yo ignoro si los conocimientos del poeta era tan amplios en datos, supongo que no. Pero la milenaria herencia de andaluz, la peculiar inteligencia propia y la cultura adquirida luego, dieron lugar a dos tragedias sorprendentes, totalmente griegas: Son rituales que, tienen lugar a propósito de ocasiones concretas; que se ejecutan de acuerdo con unas formas: alternado solista/coro; monodias aisladas; dialógicos de diversa índole-crótico hombre/ mujer, erótico madre/novio, agón generacional padre/novio; diálogos líricos - así el ditirambo hombre/hembra con hierós gámos en Yerma, treno con que acaba Bodas. Grandes corales de estructuras complejas: Himeneo, persecusión en comos, desmòs hymnos o «canto de encadenamiento» de la Luna y la Mendiga.

Así que el camino recorrido por Lorca coincide con el que conocemos bien por la literatura griega, que es éste: De una saga sale lo que llamamos poesía épica, narración

12 En «Juego y teoria del duende», Agull.Ar, págs. 118-119. 
de un pasado que fue historia. Es lo que leyó Lorca en el $A B C$. La saga no tiene por qué estar vinculada al rito y al culto -la épica no lo está-. En cambio esa otra cosa que llamamos lírica sí nació vinculada al rito y al culto. De la fusión de todo ello nació la tragedia, que es lo que Lorca pretende hacer y lo hace magistralmente.

Procedo ahora a analizar en detalle algunos elementos rituales insertados en diferentes estructuras formales. Son las siguientes:

I. Estructuras agonales.

II. Monodias.

III. Algunas innovaciones importantes de Lorca.

\section{Estructuras agonales}

Por agón se entiende todo enfrentamiento que procede de la esfera ritual, ya sea de acción, o de palabra; entre coro/actor, entre dos coros o entre dos actores.

Hay agones corales o mixtos de búsqueda y persecución que, a veces termina en sacrificio y muerte.

Agones vinculados a rituales de expulsión de la Muerte, del Invierno, del fármaco.

También agones de tipo fictivo, derivados al fin de rituales de primavera. Me refiero a los Epitalamios.

El treno o canto de duelo formaba ritualmente parte de un agón, en el que había juegos deportivos, competiciones reales.

Y están todavía los agones individuales: actor/actor de diverso tipo. Se da el enfrentamiento macho/hembra, en dos vertientes: puede ser puro enfrentamiento de sexos, o puede ser erótico. En enfrentamientos generacionales, etc ${ }^{13}$.

Ritual, como la griega, es toda la tragedia de Lorca. Así que el término agón es el que le corresponde; aunque con frecuencia se anticipan, o, prolongan con estructuras simplemente dialógicas, puramente literarias ya. Veamos esas estructuras:

\section{I.1. Agones eróticos en recitativo o lírico}

Bodas se abre con un agón madre/novio. Es algo conocido por la literatura griega, en la que se encuentra la situación inversa madre/novia.

Los datos griegos para nosotros son escasos y transmitidos muy fragmentariamente, pero los conocían bien los poetae novi, como se ve por Catulo.

El Fr. 102 de Safo refleja un diálogo entre una hija enamorada y su madre. Le dice la hija a la madre:

13 Cf. sobre el tema F. Auranus: Fiesta. Comedia y Tragedia, Barcelona. 
«Dulce madre, no puedo trabajar el telar: me derrota el amor por un muchacho por obra de Afrodita floreciente».

Y totalmente conservado está el diálogo entre Infigencia - Clitemnestra de la Ifigenia en Aulide de Eurípides, donde la doncella manifiesta sus temores y la madre la aconseja.

Lo mismo se puede decir del Fr. 107 de Safo, en el diálogo entre novia/virginidad.

Novia: « ¿Virginidad, virginidad a dónde vas dejándome?

Virginidad: «No volveré a ti, no volveré.

Lorca procede de dos maneras en Bodas:

En el agón madre/novio ha efectuado una inversión: es el novio el que ansía trabajar y a ello le incita el amor, él es el que no alberga temores. La madre quiere, pero no puede ocultar sus miedos.

Este agón adquiere su climax en el dialógico, no agonal, que sigue madre/vecina. El tema del crimen de sangre que se hereda, anticipado solo, ahora se convierte en nuclear. Es el tema de la trilogía de Esquilo. El climax se hace álgido con esta pregunta de la madre: «¿Oye, tú conoces a la novia de mi hijo?». Y, a lo largo del diálogo, se produce una anágnorisis -descubrimiento de la verdad-: «Su primer novio, Leonardo, es de la familia de los Félix»:

En cambio en el diálogo criada/novia no hay ninguna mutación. En él están las reminiscencias del diálogo de Safo: virginidad/novia.

Hay múltiples agones eróticos hombre/mujer en las dos tragedias. Vasta con analizar el diálogo Leonardo/novia de Bodas y lo tres Yerma/Víctor, en tensión creciente, de Yerma.

De ellos hay datos conservados muy superiores en número. Son muy interesantes los de la lírica popular. En el Fr. 853 del PMG, la mujer se despide del hombre porque llega la aurora.

«¿Que es lo que te pasa? No nos delatemos ambos, te lo ruego. Antes de que él llegue, levántate, no te vaya a causar un gran infortunio a ti, y también a mí, la desdichada. Ya es de día: ¿no ves la luz por la ventana?

Más interesante es el Anónimo de Marissa, texto epigráfico encontrado en Palestina, del siglo II a.C.

Mujer: «Nada siento por ti ni tengo por qué concederte favores y hasta duermo con otro, amándote tanto. Pero, por Afrodita, mucho me alegro de que tu mano me quede en prenda».

Hombre: «Pues yo me voy y te dejo el campo libre. Haz lo que quieras».

Mujer: «No llames golpeando el muro, harás ruido, sino que, a través de la puerta, te llegará una señal».

is Las traducciones al español están tomadas de las de F. Adramos, Lírica griega arcaica, Madrid. 
Hay muchos datos en Safo heterosexuales y homosexuales. En el Fr. 121 y el Fr. 137 hay un diálogo entre un hombre y una mujer que lo rechaza, dicen así:

Fr. 121

«Sigue siendo amigo mio y búscate otra mujer más joven: pue no podré vivir contigo siendo yo más vieja»

Fr. 137

Hombre: «Quiero decir algo, pero la vergüenza me lo impide».

Mujer: «Si tuvieras deseos de cosas justas y hermosas y tu lengua no removiera decir algo dañino, la vergüenza no ocuparía tus ojos sino que hablarías de los que es justo».

Entre los homosexuales hay algunos importantes:

Fr. 55. donde se ataca a una rival:

«Una vez muerta, yacerás y no habrá recuerdo tuyo ni añoranza: no tienes parte de las rosas de Pieria, sino que ignorada también en la mansión de Hades errarás revoloteando entre las sombras de los muertos:

Fr. 94: se manifiesta el deseo de la muerte por causa del desamor:

«Quicro morirme sin engaño, clla me abandonó engañándome... y me dijo muchas veces: «iAy! qué cosa más horrible nos ha pasado, Safo, de verdad que te dejo mal de mi grado». Y yo le contesté: «Marcha contenta y acuérdate de mi, pues sabes cómo te queríamos... Y si no, quiero recordarte... y éramos felices, pues muchas coronas de violetas y de rosas... también... junto a mi te ponías y muchas guirnaldas trenzadas en torno a tu cuello delicado, hechas de flores... con ungüento de brento... te frotabas y con ünguento real y sobre un lecho la delicada... dabas salida a tus deseos. Y no había... ni templo ni bosque sagrado... al que no fuéramos...».

En Lorca, se encuentra todo ello: en Bodas hay un agón, que precede al himeneo, entre Leonardo-Novia de enfrentamiento y rechazo pero también recuerdo del pasado, precedido de un paraklauthyron -llamada a la puerta de la mujer-, pero donde la puerta a la esperanza queda abierta, dice así la Novia a Leonardo:

«No puedo oírte. No puedo oír tu voz. Es como si me bebicra una botella de anís y me durmiera en una colcha de rosas. Y me arrastra, y sé que me ahogo, pero voy detrás».

La Novia añora y pide la muerte después de la pérdida del amor que supuso la muerte de Leonardo, trás consumar la boda sagrada en el bosque.

En Yerma se invierten los términos en los agones eróticos Yerma/Víctor, en este sentido: Es la heroína quien solicita, a través de sus rememoraciones del pasado, no el hombre, él ama y por eso huye. En este caso la inversión se debe a las claras reminiscencias de la Fedra de la tragedia Hipólito de Eurípides.

Se llora y hay regocijo entre la Novia y dos doncellas después de la boda en Bodas. La estructura es dialógica. Es el tema del alfiler que lo solicitan de la recién desposada: 
dolor de la pérdida de la virginidad, pero esperanza de perderla. En Lorca es la última parte del Epitalanio. Lo que precede son los elogios a los novios y la canción de albada; la estructura literaria es mixta: o sea alterna lírico y recitativo, es un epirrema.

Lorca ha invertido el orden que conocemos bien por Catulo y Teócrito, cuya fuente es Safo.

El esquema se refiere a las canciones de los dos cortejos de bodas, el de los jóvenes y el de las muchachas, encabezados por el novio y la novia. Siguiendo motivos tradicionales en la boda hay un previo enfrentamiento de sexos. Hay elogios a la novia y al novio. Intercambio de corales entre los dos coros-dialógico-. Luego el coro de hombres lleva al novio hasta la cámara nupcial.

Hay la canción que desea a los novios «un noche doblemente larga» y la canción de albada, que despierta a los esposos.

Veamos:

1. Previo enfrentamiento de sexos:

Fr. 105: la novia es como el jacinto pisoteado en las montañas.

«Como el jacinto en las montañas los pastores con sus pies lo pisan y en el suclo...».

Fr, 104: se llora el alejamiento de la novia de la casa de su madre, dice así:

«Lucero de la tarde, te traes todas las cosas que la Aurora brillante hizo salir de casa: traes la cabra, traes a la hija lejos de su madre».

2. Elogios a los dos novios:

Fr. 105: la novia es la manzana.

«Como la manzana dulce se colorea en la rama más alta, la más alta en la más alta, de ella se olvidaron los cosecheros de manzanas. Pero no es la que olvidaron, es que no pudieron alcanzarla».

Fr. 115: el novio es como un lozano sarmiento.

«i, A quién, novio, compararte con verdad? A un sarmiento lozano de vid te comparo».

Fr. 111: el coro de hombres lleva al novio a la cámara nupcial.

«Arriba el techo, himeneo, levantadlocarpinteros: himeneo ya llega el novio igual a Ares, himeneo, mucho más alto que un hombre alto».

3. El deseo de una noche doblemente larga y la canción de albada.

En el fr. 30 ésta parte de la canción de albada.

«La noche... las doncellas... festejando en la noche... cantan tu amor y el de la novia de senos de violeta. Despiértate, novio, ven con los amigos de tu edad... para que veamos menos sueños que el ruiseñor de agudo canto».

En Bodas se observan unos ecos sorprendentes en Epitalamio. Pero no se debe esperar copia, no se da en ningún verdadero poeta. Aquí la canción de albada precede a la boda. 
Después van los elogios al novio y a la novia. Si se lee a Lorca, conociendo a Catulo, a Teócrito, a Safo, se hace imposible pensar que no los hubiera leído. Como leía Lorca, a salto de mata, buscando lo que «le sugería» más de entre su mundo de vivencias y de su mente privilegiada. Ya dije antes que «fue un lector y un oyente muy selectivo».

La estructura literaria es compleja y merece la pena decir algo de ella. Es lírico, no dialógico. Hay un coro asexuado -Voces-.

«Despierte la novia

la mañana de la boda»

Ese coro se concretiza luego en dos semicoros: el de muchachas y el de mozos. Esa estructura es puramente griega y ritual.

Pero lo asombroso son las innovaciones de Lorca; determinadas por una intencionalidad. Son las siguientes:

1. Tanto el coro de muchachas como el de mozos canta a la novia.

2. No hay por tanto corega y corego.

3. Los actores: Novia -Criada - Padre funcionan, alternadamente como solistas.

4. Los elogios al novio, que siguen a la canción de albada y se insertan en ella, está en labios del coro de muchachas y, sólo es formalmente una corta espansión literaria. Lo pertinente es la Novia.

5. La utilización del estribillo: «iDespierte la novia!, es interesante. Y ello por las siguientes razones:

5.1. En la literatura clásica el estribillo está a cargo del coro. Aquí se ha efectuado una amalgama literaria, o sea, el estribillo lo canta tanto cl coro, o, los coros, como la primera solista, que es la Novia, que lo inicia. Después, el estribillo «iDespierte la novia!» se repite nada más que en las voces, o sea, el coro asexuado. Tanto el coro de muchachas, como el de mozos, cuando comienzan con el estribillo añaden siempre nueva y diferente información. Tipo

Muchacha $1^{\mathrm{a}}$

«Despierte la novia

la mañana de la boda;

ruede la ronda

balcón una corona.

O Mozo $1^{\circ}$

«Despierte la novia, que por los campos viene

rodando la boda, con bandejas de dalias

y panes de gloria». 